\title{
SISTEM PENDUKUNG KEPUTUSAN PEMILIHAN GURU BERPRESTASI MENGGUNAKAN METODE PROMETHEE (Studi Kasus: Dinas Pendidikan Kota Malang)
}

\author{
Febryan Senja Priyanto $^{1}$, Budi Harijanto ${ }^{2}$, Yan Watequlis ${ }^{3}$ \\ ${ }^{1,2,3}$ Program Studi Teknik Informatika, Jurusan Teknologi Informasi, Politeknik Negeri Malang \\ ${ }^{1}$ feb93senja@gmail.com, ${ }^{2}$ budi.hijet@gmail.com, ${ }^{3}$ yan_watequlis@polinema.ac.id
}

\begin{abstract}
Abstrak
SPK (Sistem pendukung keputusan) ini digunakan sebagai alat untuk lomba pemilihan guru berprestasi dan ditujukan kepada Dinas Pendidikan Kota Malang dimana pada proses perhitungannya masih menggunakan sistem manual dalam menilai para peserta guru berprestasi. Sistem ini diharapkan dapat membantu pihak dinas dalam proses penilaian dan penentuan guru berprestasi di wilayah Kota Malang secara cepat, tepat dan akurat. Metode yang digunakan dalam sistem pendukung keputusan pemilihan guru berprestasi ini adalah metode Promethee. Yaitu salah satu metode yang termasuk dalam kelompok pemecahan masalah Multi Criteria Decision Making (MCDM). Hasil dari perangkingan dalam sistem ini dipengaruhi oleh pemilihan tipe preferensi dan penentuan threshold yang diinputkan ke dalam sistem. Sehingga, hasilnya ada yang sama dan ada yang tidak sama dengan proses seleksi manualnya. Pengujian sistem ini menggunakan data nilai dari 10 guru, yang perangkingannya dibagi menurut kelompok SMK dan SMA. Dari beberapa ujicoba yang telah dilakukan untuk menentukan guru berprestasi, hasil perangkingannya jauh lebih cepat dan lebih akuntabel.
\end{abstract}

Kata Kunci: sistem pendukung keputusan, pemilihan guru berprestasi, metode promethee

\section{Pendahuluan}

Pendidikan nasional berfungsi mengembangkan kemampuan dan membentuk watak serta peradaban bangsa yang bermartabat dalam rangka mencerdaskan kehidupan bangsa. Sejalan dengan itu, di dalam Undang-Undang Republik Indonesia Nomor 20 Tahun 2003 tentang Sistem Pendidikan Nasional disebutkan bahwa pendidikan nasional bertujuan untuk mengembangkan potensi peserta didik agar menjadi manusia yang beriman dan bertakwa kepada Tuhan Yang Maha Esa, berakhlak mulia, sehat, berilmu, cakap, kreatif, mandiri, dan menjadi warga Negara yang demokratis serta bertanggung jawab. Pemilihan Guru SMA dan Guru SMK Berprestasi Tahun 2016 merupakan salah satu implementasi UndangUndang Republik Indonesia Nomor 14 Tahun 2005 dan Peraturan Pemerintah Republik Indonesia Nomor 74 Tahun 2008. Guru SMA dan Guru SMK Berprestasi merupakan Guru SMA dan Guru SMK yang dapat menjadi model atau contoh bagi Guru SMA dan Guru SMK lainnya. Guru tersebut mempunyai prestasi yang luar biasa atau melebihi yang dicapai guru SMA dan Guru SMK lain. Pemilihan guru berprestasi diharapkan berdampak positif bagi perkembangan pendidikan dan peningkatan mutu dan proses hasil pembelajaran. Melalui pemilihan Guru SMA dan Guru SMK berprestasi diharapkan semua pemangku kepentingan akan meningkatkan komitmennya dalam pembinaan dan pengembangan profesionalisme guru untuk mewujudkan pendidikan yang bermutu.

Maka dari itu, dibutuhkan suatu sistem pendukung keputusan pemilihan guru prestasi yang dapat memotivasi guru untuk melakukan kewajibannya dengan baik sehingga tercapai suatu keputusan yang baik dan optimal. Sistem pendukung keputusan ini juga berfungsi sebagai aplikasi yang dapat membantu untuk mendukung keputusan dalam pemilihan guru prestasi secara cepat dan akurat dengan cara memberikan alternatif pengambilan keputusan yang baik. Dalam penentuan rangking calon guru berprestasi, sistem pendukung keputusan ini menggunakan metode Promethee yang mampu memilih alternatif terbaik dari beberapa alternatif dan menggunakan lebih dari satu kriteria (multikriteria).

Oleh karena itu, dilakukan suatu perancangan dan pembangunan sistem pendukung keputusan pemilihan guru berprestasi menggunakan metode Promethee. Yaitu merupakan metode perangkingan dengan melakukan perbandingan untuk masingmasing alternative sehingga menghasilkan output urutan/rangking guru berprestasi. Ada 2 tahap 
perangkingan dalam metode promethee yaitu promethee I (Leaving Flow dan Entering Flow) dan Promethee II (Net Flow). Pada Net Flow merupakan acuan sebagai output akhir untuk menghasilkan perangkingan guru berprestasi.

Sistem pendukung keputusan pemilihan guru berprestasi ini diharapkan dapat membantu pihak dinas atau instansi dalam pengambilan keputusan yang berhubungan dengan guru. Sistem pendukung keputusan ini juga berfungsi untuk mengantisipasi subyektifitas penilai dalam menilai peserta guru berprestasi. Sehingga, pemilihan guru berprestasi dapat menghasilkan guru-guru yang memang berprestasi dalam bidang pendidikan baik dalam kegiatan formal dan non formal. Selain itu, sistem ini membantu dalam pendataan yang berhubungan dengan kegiatan pemilihan guru berprestasi sehingga data-data yang dibutuhkan terorganisir dengan baik dalam database.

\section{Landasan Teori}

\subsection{Sistem Pendukung Keputusan}

Sistem Pendukung Keputusan (SPK) atau Decision Support System (DSS) adalah sebuah sistem yang mampu memberikan kemampuan pemecahan masalah maupun kemampuan pengkomunikasian untuk masalah dengan kondisi semi terstruktur dan tak terstruktur. Sistem ini digunakan untuk membantu pengambilan keputusan dalam situasi semi terstruktur dan situasi yang tidak terstruktur, dimana tak seorangpun tahu secara pasti bagaimana keputusan seharusnya dibuat (Turban, 2001).

SPK merupakan implementasi teori-teori pengambilan keputusan yang telah diperkenalkan oleh ilmu-ilmu seperti operation research dan menegement science, hanya bedanya adalah bahwa jika dahulu untuk mencari penyelesaian masalah yang dihadapi harus dilakukan perhitungan iterasi secara manual (biasanya untuk mencari nilai minimum, maksimum, atau optimum), saat ini computer PC telah menawarkan kemampuannya untuk menyelesaikan persoalan yang sama dalam waktu relatif singkat.

\subsection{Preference Ranking Organization Method for Enrichment Evaluation (PROMETHEE)}

Promethee adalah suatu metode penentuan urutan (prioritas) dalam analisis multikriteria. Masalah pokoknya adalah kesederhanaan, kejelasan, dan kestabilan. Dugaan dari dominasi kriteria yang digunakan dalam Promethee adalah penggunaan nilai dalam hubungan outranking. Metode ini termasuk metode peringkat yang cukup sederhana dalam konsep dan aplikasi dibandingkan dengan metode lain untuk analisis multikriteria. Untuk setiap kriteria, fungsi preferensi menerjemahkan perbedaan antara dua alternatif menjadi derajat preferensi mulai dari nol sampai satu.

Struktur preferensi Promethee berdasarkan perbandingan berpasangan. Semakin kecil nilai deviasi maka semakin kecil nilai preferensinya, semakin besar deviasi semakin besar preferensinya. Dalam rangka memfasilitasi pemilihan fungsi preferensi tertentu, Brans dan Vincke, mengusulkan enam tipe dasar.

Berikut Gambar tipe Preferensi dasar pada Metode Promethee :

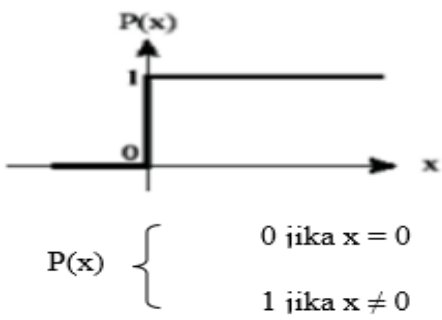

Gambar 1 Tipe Preferensi Usual (Tipe I)

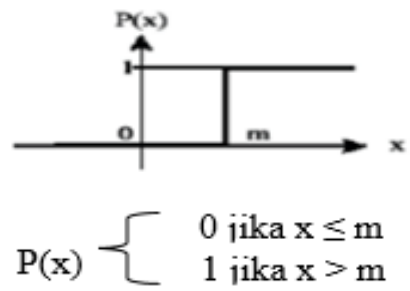

Gambar 2 Tipe Preferensi Quasi (Tipe II)

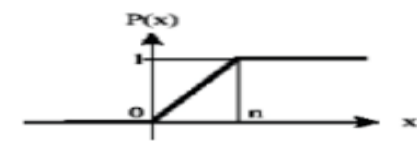

$\mathrm{P}(\mathrm{x})\left\{\begin{array}{l}\mathrm{x} / \mathrm{n} \text { jika } 0 \leq \mathrm{x} \leq \mathrm{n} \\ 1 \text { jika } \mathrm{x}>\mathrm{n}\end{array}\right.$

Gambar 3 Tipe Preferensi Linear (Tipe III)

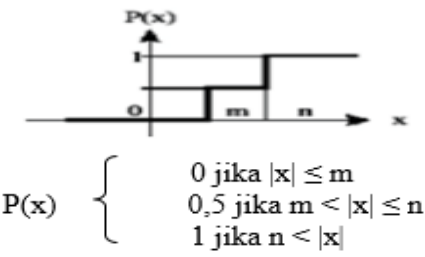

Gambar 4 Tipe Preferensi Level (Tipe IV)

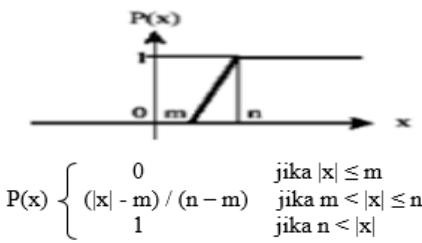

Gambar 5 Tipe Preferensi Linear Quasi (Tipe VI) 
Tipe Gaussian (Gaussian Criterion) / Tipe VI

Fungsi ini bersyarat apabila telah ditentukan nilai $\sigma$. Seperti rumus di bawah ini :

$\mathrm{H}(\mathrm{d})=1-\exp \left\{-\mathrm{d}^{2} / 2 \sigma^{2}\right\}$

Arah dalam grafik nilai outrangking

Perangkingan yang digunakan dalam

metode promethee meliputi tiga bentuk antara lain:

\section{Leaving Flow}

Sedangkan Leaving flow adalah jumlah dari yang memiliki arah menjauh dari node a dan hal ini merupakan pengukuran outrangking. Adapun rumusnya:

$$
\phi^{+}(a)=\frac{1}{n-1} \sum_{x \in A} \wp(\mathrm{a}, \mathrm{x})
$$

\section{Entering flow}

Entering flow adalah jumlah dari yang memiliki arah mendekat dari node a dan hal ini merupakan karakter pengukuran outrangking. Untuk setiap nilai node a dalam grafik nilai outrangking ditentukan berdasarkan entering flow dengan rumus:

$$
\phi^{-}(a)=\frac{1}{n-1} \sum_{x \in A} \wp(\mathrm{x}, \mathrm{a})
$$

\section{Net Flow}

Sehingga pertimbangan dalam penentuan $\mathrm{Net}$ flow diperoleh dengan rumus :

$$
\phi(a)=\phi^{+}(a)-\phi^{-}(a)
$$

Semakin besar nilai Leaving flow dan semakin kecil Entering flow maka alternatif tersebut memiliki kemungkinan dipilih yang semakin besar. Perangkingan dalam PROMETHEE I dilakukan secara parsial yaitu didasarkan pada nilai Entering flow dan Leaving flow.

Sedangkan PROMETHEE II termasuk perangkingan komplek karena didasarkan pada nilai Net flow masing-masing alternatif yaitu alternatif dengan nilai Net flow lebih tinggi menempati satu rangking yang lebih baik.

\subsection{Prosedur Penilaian Pemilihan Guru Berprestasi}

Tabel 1 Tabel Bobot

\begin{tabular}{|c|c|}
\hline Aspek & Bobot (\%) \\
\hline Dokumen Portofolio & 10 \\
\hline Penilaian Kinerja Guru & 20 \\
\hline Rencana Pelaksanaan Pembelajaran & 10 \\
\hline Presentasi Karya Ilmiah & 25 \\
\hline Wawancara & 20 \\
\hline Tes Tulis & 15 \\
\hline
\end{tabular}

\section{Metodologi Penelitian}

\subsection{Pengumpulan Data}

Metode pengumpulan data pada penelitian ini adalah metode survey. Metode survey merupakan metode pengumpulan data yang diperoleh secara langsung dari responden yang relevan.

\subsection{Metode Pengolahan Data}

Dalam tahapan ini akan diformulasikan model yang akan digunakan serta kriteria-kriteria yang ditentukan. Pada masing-masing kriteria akan diberikan threshold $\mathrm{p}, \mathrm{q}$ dan g. Dan juga kaidah minimasi dan maksimasi. Karena pada basis pengetahuan metode promethee terdapat 6 tipe preferensi yang dimana hasil akhirnya bergantung pada jenis tipe preferensi,kaidah min-maks dan juga threshold yang ditentukan oleh pengambil keputusan sehingga menghasilkan output berupa rangking alternatif. Output dari sistem ini sendiri adalah urutan rangking guru berprestasi.

Model yang diterapkan adalah metode PROMETHEE (Preference Ranking Organization Method for Enrichment Evaluation). Ada 7 proses dalam perhitungan promethee.

Tabel 2 adalah Data Nilai peserta, data kriteria, kaidah Min-maks, bobot, tipe preferensi dan

\begin{tabular}{|c|c|c|c|c|c|c|c|c|c|c|}
\hline \multirow{2}{*}{ Kriteria } & \multirow{2}{*}{ Min Maks } & \multirow{2}{*}{ bobot } & \multicolumn{5}{|c|}{ Alternatif } & \multirow{2}{*}{$\begin{array}{c}\text { Tipe } \\
\text { Preferensi }\end{array}$} & \multicolumn{2}{|c|}{ Parameter } \\
\hline & & & G1 & $\mathrm{G} 2$ & G3 & G4 & G5 & & $q$ & p \\
\hline $\mathrm{F} 1$ & Maksimasi & 0.1 & 320 & 330 & 310 & 310 & 305 & 3 & 0 & 100 \\
\hline $\mathrm{F} 2$ & Maksimasi & 0.2 & 80 & 78 & 83 & 86 & 80 & 3 & 0 & 100 \\
\hline F3 & Maksimasi & 0.1 & 92 & 88 & 93 & 84 & 87 & 3 & 0 & 100 \\
\hline F4 & Maksimasi & 0.25 & 11 & 12 & 12 & 6 & 10 & 3 & 0 & 100 \\
\hline F5 & Maksimasi & 0.2 & 18 & 16 & 17 & 17 & 14 & 3 & 0 & 100 \\
\hline F6 & Maksimasi & 0.15 & 78 & 80 & 68 & 82 & 76 & 3 & 0 & 100 \\
\hline
\end{tabular}
threshold yang diberikan. (Proses 1,2,3 dan 4).

Tabel 2 Nilai dan Kriteria

Pada Tabel 2, nilai peserta diambil dari 5 sampel nilai peserta yang didapat dari Dinas Pendidikan Kota Malang.

Tipe Preferensi adalah tipe preferensi 3 dengan threshold $\mathrm{p}=100$ dan kaidah yang digunakan adalah kaidah maksimasi. Artinya lebih disukai adalah nilai maksimum.

Setelah itu dilanjutkan ke proses ke 5 yaitu Proses Preferensi .

Tipe Preferensi III

$$
\mathrm{H}\left\{\begin{array}{l}
\mathrm{d} / \mathrm{p} \text { iika } 0 \leq \mathrm{d} \leq \mathrm{p} \\
1 \text { jika } \mathrm{d}>\mathrm{p}
\end{array}\right.
$$

Keterangan :

$\mathrm{d}=$ selisih/deviasi $\quad \mathrm{p}=$ Threshold $\mathrm{p}$

G1 - G5 = peserta $\quad$ F1-F6 $=$ Kriteria

Kriteria $\mathrm{F} 1$ =

Tipe III dengan $\mathrm{p}=100$

$\mathrm{d}=320-330=-10$ 
karena maksimasi dan $\mathrm{a}<\mathrm{b}$ maka $\mathrm{P}(\mathrm{A}, \mathrm{B})=0$, dan $\mathrm{P}(\mathrm{B}, \mathrm{A})=0,1$

Kriteria F2

Tipe III dengan $\mathrm{p}=100$

$\mathrm{d}=80-78=2$

karena maksimasi dan $\mathrm{a}>\mathrm{b}$ maka $\mathrm{P}(\mathrm{A}, \mathrm{B})=0.02$,

$\mathrm{P}(\mathrm{B}, \mathrm{A})=0$

Kriteria F3

Tipe III dengan $\mathrm{p}=100$

$\mathrm{d}=92-88=4$

karena maksimasi dan $\mathrm{a}>\mathrm{b}$ maka $\mathrm{P}(\mathrm{A}, \mathrm{B})=0.04$, $\mathrm{P}(\mathrm{B}, \mathrm{A})=0$

Kriteria F4

Tipe III dengan $\mathrm{p}=100$

$\mathrm{d}=11-12=-1$

karena maksimasi dan $\mathrm{a}<\mathrm{b}$ maka $\mathrm{P}(\mathrm{A}, \mathrm{B})=0, \mathrm{P}(\mathrm{B}, \mathrm{A})$ $=0.01$

Kriteria F5

Tipe III dengan $\mathrm{p}=100$

$\mathrm{d}=18-16=2$

karena maksimasi dan $\mathrm{a}>\mathrm{b}$ maka $\mathrm{P}(\mathrm{A}, \mathrm{B})=0.02$, $\mathrm{P}(\mathrm{B}, \mathrm{A})=0$

Kriteria F6

Tipe III dengan $\mathrm{p}=100$

$\mathrm{d}=78-80=-2$

karena maksimasi dan $\mathrm{a}<\mathrm{b}$ maka $\mathrm{P}(\mathrm{A}, \mathrm{B})=0, \mathrm{P}(\mathrm{B}, \mathrm{A})$ $=0.02$

Setelah dilakukan perbandingan berpasangan semua alternatif terhadap kriteria maka tiap index preferensi dikalikan dengan bobot masing-masing kriteria.

Dan tabel 3 adalah tabel total index preferensi.

Tabel 3 Total Indeks Preferensi

\begin{tabular}{|l|l|r|}
\hline \multicolumn{3}{|c|}{ Total Index Preferensi } \\
\hline G1 & G2 & 0.002 \\
\hline G2 & G1 & 0.002583333 \\
\hline G1 & G3 & 0.0045 \\
\hline G3 & G1 & 0.001583333 \\
\hline G1 & G4 & 0.02075 \\
\hline G4 & G1 & 0.003 \\
\hline G1 & G5 & 0.005583333 \\
\hline G5 & G1 & 0 \\
\hline G2 & G3 & 0.006333333 \\
\hline G3 & G2 & 0.002833333 \\
\hline G2 & G4 & 0.0065 \\
\hline G4 & G2 & 0.0035 \\
\hline G2 & G5 & 0.006833333 \\
\hline G5 & G2 & 0.000666667 \\
\hline G3 & G4 & 0.019166667 \\
\hline G4 & G3 & 0.0045 \\
\hline G3 & G5 & 0.004666667 \\
\hline G5 & G3 & 0.002 \\
\hline G4 & G5 & 0.005333333 \\
\hline G5 & G4 & 0.002166667 \\
\hline
\end{tabular}

Tabel 3 tersebut kemudian dibuat matriks untuk dilakukan perhitungan mencari nilai Leaving Flow dan Entering Flow (Proses 6).
Tabel 4 Tabel Proses Promethee I

\begin{tabular}{|c|c|c|c|c|c|c|c|}
\hline $\begin{array}{l}\text { Peser } \\
\text { ta }\end{array}$ & G1 & G2 & G3 & G4 & G5 & $\begin{array}{l}\text { Juml } \\
\text { ah }\end{array}$ & $\begin{array}{l}\text { Leav } \\
\text { ing } \\
\text { Flow }\end{array}$ \\
\hline G1 & 0 & 0.002 & $\begin{array}{l}0.00 \\
45\end{array}$ & $\begin{array}{l}0.02 \\
075\end{array}$ & $\begin{array}{l}0.00 \\
5583 \\
333 \\
\end{array}$ & $\begin{array}{l}0.03 \\
2833 \\
333 \\
\end{array}$ & $\begin{array}{l}0.00 \\
8208 \\
333 \\
\end{array}$ \\
\hline G2 & $\begin{array}{l}0.0 \\
02 \\
58 \\
33 \\
33\end{array}$ & 0 & $\begin{array}{l}0.00 \\
6333 \\
333\end{array}$ & $\begin{array}{l}0.00 \\
65\end{array}$ & $\begin{array}{l}0.00 \\
6833 \\
333\end{array}$ & $\begin{array}{l}0.02 \\
225\end{array}$ & $\begin{array}{l}0.00 \\
5562 \\
5\end{array}$ \\
\hline G3 & $\begin{array}{l}0.0 \\
01 \\
58 \\
33 \\
33\end{array}$ & $\begin{array}{l}0.0028 \\
33333\end{array}$ & 0 & $\begin{array}{l}0.01 \\
9166 \\
667\end{array}$ & $\begin{array}{l}0.00 \\
4666 \\
667\end{array}$ & $\begin{array}{l}0.02 \\
825\end{array}$ & $\begin{array}{l}0.00 \\
7062 \\
5\end{array}$ \\
\hline G4 & $\begin{array}{l}0.0 \\
03\end{array}$ & 0.0035 & $\begin{array}{l}0.00 \\
45\end{array}$ & 0 & $\begin{array}{l}0.00 \\
5333 \\
333 \\
\end{array}$ & $\begin{array}{l}0.01 \\
6333 \\
333 \\
\end{array}$ & $\begin{array}{l}0.00 \\
4083 \\
333 \\
\end{array}$ \\
\hline G5 & 0 & $\begin{array}{l}0.0006 \\
66667\end{array}$ & $\begin{array}{l}0.00 \\
2\end{array}$ & $\begin{array}{l}0.00 \\
2166 \\
667 \\
\end{array}$ & 0 & $\begin{array}{l}0.00 \\
4833 \\
333\end{array}$ & $\begin{array}{l}0.00 \\
1208 \\
333\end{array}$ \\
\hline $\begin{array}{l}\text { Juml } \\
\text { ah }\end{array}$ & $\begin{array}{l}0.0 \\
07 \\
16 \\
66 \\
67\end{array}$ & 0.009 & $\begin{array}{l}0.01 \\
7333 \\
333\end{array}$ & $\begin{array}{l}0.04 \\
8583 \\
333\end{array}$ & $\begin{array}{l}0.02 \\
2416 \\
667\end{array}$ & & \\
\hline $\begin{array}{l}\text { Enter } \\
\text { ing } \\
\text { Flow }\end{array}$ & $\begin{array}{l}0.0 \\
01 \\
79 \\
16 \\
67 \\
\end{array}$ & $\begin{array}{l}0.0022 \\
5\end{array}$ & $\begin{array}{l}0.00 \\
4333 \\
333\end{array}$ & $\begin{array}{l}0.01 \\
2145 \\
833\end{array}$ & $\begin{array}{l}0.00 \\
5604 \\
167\end{array}$ & & \\
\hline
\end{tabular}

Tabel 4 adalah tabel matriks Proses Promethee I (Leaving Flow dan Entering Flow). Dan setelah itu dilakukan perhitungan (proses 7) Promethee II (Net Flow), dimana proses ini sebagai hasil akhir perangkingan.

Tabel 5 Tabel Proses Promethee II

\begin{tabular}{|l|l|l|l|l|}
\hline $\begin{array}{l}\text { Pese } \\
\text { rta }\end{array}$ & Leaving Flow & $\begin{array}{c}\text { Entering } \\
\text { Flow }\end{array}$ & Net Flow & Rank \\
\hline G1 & 0.008208333 & 0.001791667 & 0.006416667 & 1 \\
\hline G2 & 0.0055625 & 0.00225 & 0.0033125 & 2 \\
\hline G3 & 0.0070625 & 0.004333333 & 0.002729167 & 3 \\
\hline G4 & 0.004083333 & 0.012145833 & -0.0080625 & 5 \\
\hline G5 & 0.001208333 & 0.005604167 & -0.004395833 & 4 \\
\hline
\end{tabular}

Dapat dilihat pada Tabel 5 bahwa Peserta G1 sebagai alternatif/peserta terbaik dengan nilai $\mathrm{Net}$ flow 0.06416667 .

\subsection{Metode Pengembangan Perangkat Lunak a. Definisi Persyaratan}

Dari hasil wawancara dengan juri ataupun petugas Dinas Pendidikan Kota Malang yang terkait dengan pemilihan guru berprestasi terdapat 6 Kriteria yang digunakan pada Tahun 2016. Untuk bobot masing-masing kriteria sendiri sudah ditentukan oleh pihak Dinas Pendidikan Kota Malang. Kriteria tersebut meliputi: Penilaian Portofolio, PKG, Penilaian RPP, Presentasi Karya Ilmiah, Wawancara dan Tes Tulis. 


\section{b. Implementasi Sistem}

Implementasi aplikasi yang menerapkan metode Promethee dilakukan berdasarkan perancangan aplikasi. Implementasi perangkat lunak dilakukan dengan mengggunakan bahasa pemograman berorientasi objek yaitu menggunakan implementasi basis data MYSQL dengan aplikasi XAMPP dan bahasa pemogrmana web (PHP, HTML, javaScript).

\section{c. Uji Coba Program}

Pada tahap ini dilakukan pengujian keberhasilan atau validasi dan akurasi sistem yang telah dibuat pada tahap implementasi. Pengujian sistem ini dilakukan agar dapat menunjukkan bahwa aplikasi dapat bekerja sesuai yang diharapkan. Pengujian sistem yang dilakukan meliputi :

\section{Analisis Dan Perancangan 4.2 Data Flow Diagram}

a. DFD Level 0

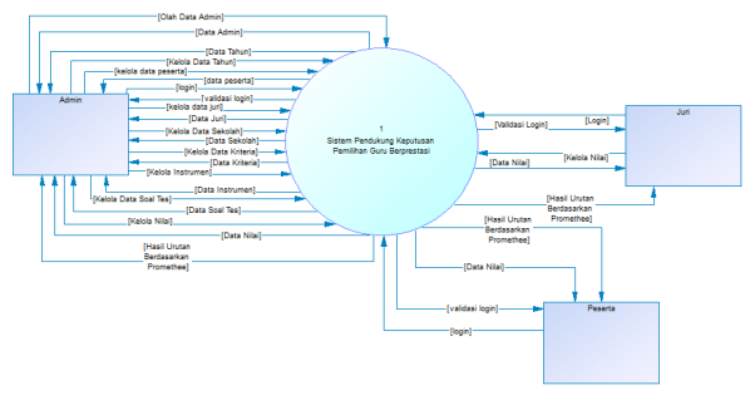

Gambar 6 DFD Level 0

Pada Gambar 6 data yang masuk dari sistem ke entitas admin adalah validasi login, data kriteria, data peserta,data juri, data tahun, data nilai peserta, data tes tulis, data instrumen dan data sekolah. Data yang masuk dari entitas juri adalah validasi login, data nilai peserta. Sedangkan peserta akan menerima hasil nilai yang sudah diinput/dinilai oleh admin ataupun juri.

\section{Implementasi}

\subsection{Implementasi Sistem}
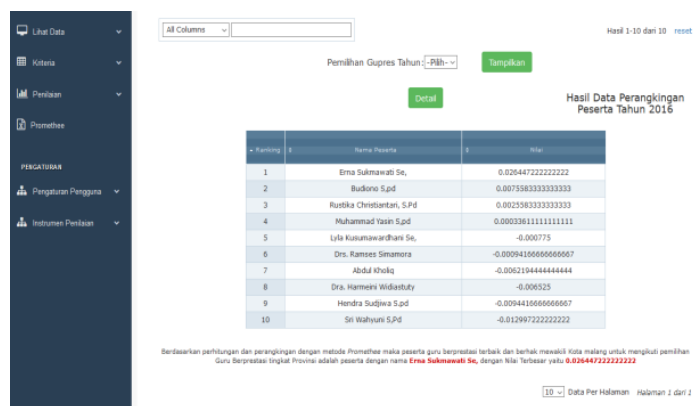

Gambar 7 Implementasi Halaman Promethee
Pada gambar 7 adalah Implementasi halaman output perangkingan peserta berdasarkan metode Promethee.

\section{Pengujian Dan Pembahasan \\ 6.1 Pengujian Hasil (Sistem)}

Pada gambar 8 berikut ini adalah data nilai peserta guru berprestasi dan kriteria Pemilihan Guru Berprestasi tahun 2016.

Tipe Preferensi yang digunakan adalah tipe Linier (Tipe III) untuk semua kriteria. Tipe III cocok digunakan untuk perhitungan yang bersifat data kuantitatif (numerik). Sedangkan threshold untuk semua kriteria adalah 100. Threshold sendiri ditentukan oleh decision maker, penulis mengikuti jejak penelitian sebelumnya. Pemberian threshold ditentukan secara simultan.

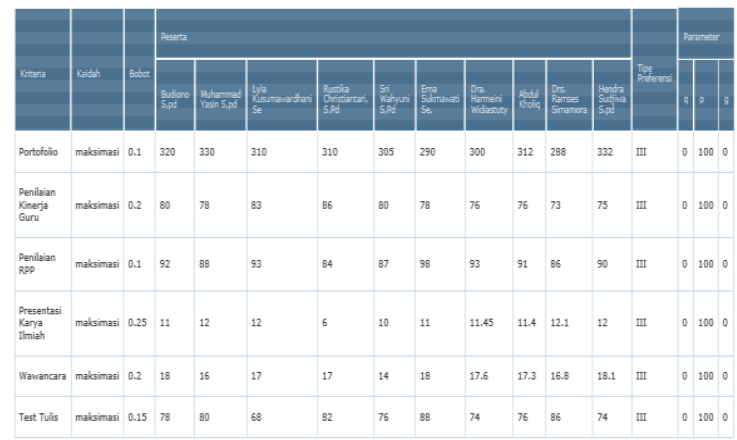

Gambar 8 Data Pemilihan Guru Berprestasi

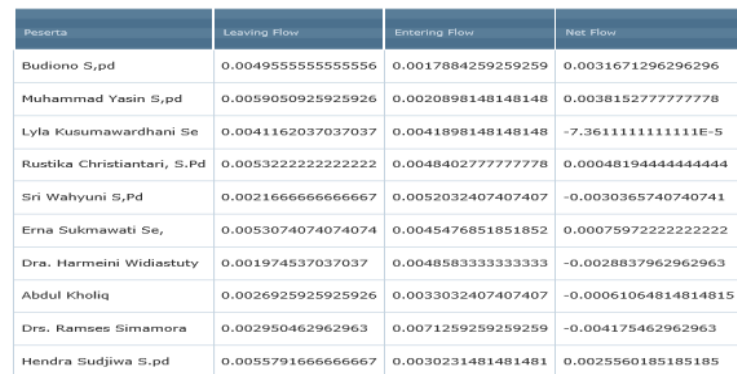

Gambar 9 Proses Promethee II (Net Flow)

Gambar 9 adalah hasil perhitungan berdasarkan matriks Indeks preferensi. Rangking Leaving Flow dan Entering Flow dikatakan sebagai Proses Promethee I. Dimana proses ini masih bersifat parsial. Sedangkan Net Flow adalah hasil akhir dari perhitungan promethee. Dan dikatakan sebagai proses Promethee II (urutan lengkap).

\subsection{Pengujian Akurasi}

Pengujian Akurasi dimaksudkan untuk membandingkan data rangking peserta tahun 2016 berdasarkan perhitungan manual (pakar) dengan perhitungan berdasarkan metode Promethee.

Dan Tabel 6 berikut ini adalah table hasil pengujian akurasi. 
Tabel 6 Pengujian Akurasi

\begin{tabular}{|l|c|c|c|}
\hline \multicolumn{1}{|c|}{ Nama Peserta } & $\begin{array}{c}\text { Peringkat } \\
\text { Pakar }\end{array}$ & $\begin{array}{c}\text { Peringka } \\
\text { t Sistem }\end{array}$ & $\begin{array}{c}\text { Akuras } \\
\text { i }\end{array}$ \\
\hline $\begin{array}{l}\text { Muhammad } \\
\text { Yasin S,Pd }\end{array}$ & 1 & 1 & $\sqrt{ }$ \\
\hline Budiono S,Pd & 2 & 2 & $\sqrt{ }$ \\
\hline $\begin{array}{l}\text { Hendra Sudjiwa } \\
\text { S,Pd }\end{array}$ & 3 & 3 & $\sqrt{ }$ \\
\hline $\begin{array}{l}\text { Erna Sukmawati } \\
\text { S,Pd }\end{array}$ & 4 & 4 & $\sqrt{ }$ \\
\hline $\begin{array}{l}\text { Rustika } \\
\text { Christiantari } \\
\text { S,Pd }\end{array}$ & 5 & 5 & $\sqrt{ }$ \\
\hline $\begin{array}{l}\text { Lyla } \\
\text { Kusumawardha } \\
\text { ni SE, }\end{array}$ & 6 & 6 & $\sqrt{ }$ \\
\hline $\begin{array}{l}\text { Drs. Abdul } \\
\text { Kholiq }\end{array}$ & 7 & 7 & $\sqrt{ }$ \\
\hline $\begin{array}{l}\text { Dra. Harmeini } \\
\text { Widyastuti }\end{array}$ & 8 & 9 & $\sqrt{ }$ \\
\hline $\begin{array}{l}\text { Sri Wahyuni } \\
\text { S,Pd }\end{array}$ & 10 & 10 & $\sqrt{ }$ \\
\hline $\begin{array}{l}\text { Drs. Ramses } \\
\text { Simamora }\end{array}$ & Presentase $(\%)$ & $100 \%$ \\
\hline \begin{tabular}{l} 
Simat \\
\hline
\end{tabular} & 7 & & \\
\hline
\end{tabular}

\section{Penutup}

\subsection{Kesimpulan}

Berdasarkan penelitian yang dilaksanakan oleh penulis pada sistem pendukung keputusan pemilihan guru berprestasi menggunakan metode promethee, dapat diambil kesimpulan sebagai berikut:

1. Suatu metode penentuan prioritas yang bisa dibilang cukup sederhana. Urutan prioritas terbaik dipengaruhi oleh tipe preferensi yang digunakan dan threshold yang sudah ditentukan oleh si pengambil keputusan.

2. Dengan membandingkan nilai alternatif/peserta kandidat juara menggunakan metode promethee, maka didapatkan urutan alternatif/peserta terbaik dengan hasil yang objektif.

3. SPK pemilihan guru berprestasi ini dapat mengurangi atau mengeliminasi kekurangkekurangan yang ada selama proses perhitungan dan penentuan peserta terbaik.

4. Berdasarkan Hasil pengujian akurasi (Tabel 6) maka dapat dikatakan bahwa SPK ini memiliki akurasi $100 \%$ dalam proses pemilihan guru berprestasi dan sistem ini bekerja sesuai dengan tujuan yang diharapkan.

\subsection{Saran}

Saran yang diberikan untuk pengembangan sistem pendukung keputusan dalam penelitian ini adalah:

1. Dilakukan pengembangan sistem agar menjadi lebih baik seperti menggabungkan metode promethee dengan metode-metode lain, dan juga penambahan beberapa fitur.

2. Karena metode promethee ini bisa dikatakan sebagai salah satu metode penentuan prioritas yang cukup sederhana, maka tak ada salahnya jika aplikasi dapat dibuat versi lain, seperti aplikasi berbasis android (mobile) ataupun berbasis desktop (visual studio).

\section{Daftar Pustaka}

Brans J.P., \& Vincke P. A, (1985): Preference Ranking Organization Method: The PROMETHEE Method For MCDM, Management Science, 31,6: pp. 647-656.

Direktorat Pembinaan Pendidik Dan Tenaga Kependidikan. Kementrian Pendidikan Nasional, (2016): Pedoman Pemilihan Guru Berprestasi SMK/SMA Tingkat Kota/Kabupaten

El Said, F., Konsep Sistem Pendukung Keputusan (SPK), [Online] Tersedia pada http://fairuzelsaid.com/konsep-sistempendukung-keputusan-spk/ [ 9 Juli 2016]

Huda, K., (2013): Sistem Pendukung Keputusan Pemilihan Siswa Terbaik Dengan Metode Promethee Berbasis Web, Diakses pada tanggal 9 Juli 2016

Little, J.D.C., (1970): Managers And Models: the Concept of a Decision Calculus, 16 (8) B pp. 466-485

McLeod, R., Jr., (1998): Information Resources Management, Management Information Systems ( $8^{\text {th }}$ Edition), 6283803

Novaliendry, D., (2015): Aplikasi Penggunaan Metode Promethee Dalam Sistem Pendukung Keputusan Untuk Penentuan Media Promosi, Mahasiswa Jurusan Teknik Elektronika Universitas Negeri Padang, Diakses tanggal 8 Juli 2016.

Promethee Method, [Online] Tersedia pada http://www.promethee-gaia.net/methods.html

The Promethee-GAIA FAQ, [Online] Tersedia pada http://www.promethee-gaia.net/faqpro/?action=article $\&$ cat_id $=003002 \&$ id $=6 \&$ lan $\mathrm{g}=$, Diakses tanggal 9 Maret 2016

Yuwono, B., (2015): Sistem Pendukung Keputusan Menggunakan Metode Promethee (Studi Kasus : Stasiun Pengisian Bahan Bakar Umum), Mahasiswa Jurusan Teknik Informatika UPN "Veteran" Yogyakarta, Diakses pada 7 Agustus 2016 